\title{
Unusual fluorescent monomeric and dimeric dialkynyl dipyrromethene-borane complexes
}

Christine Goze, Gilles Ulrich and Raymond Ziessel*

SUPPLEMENTARY MATERIALS

NMR Spectra 

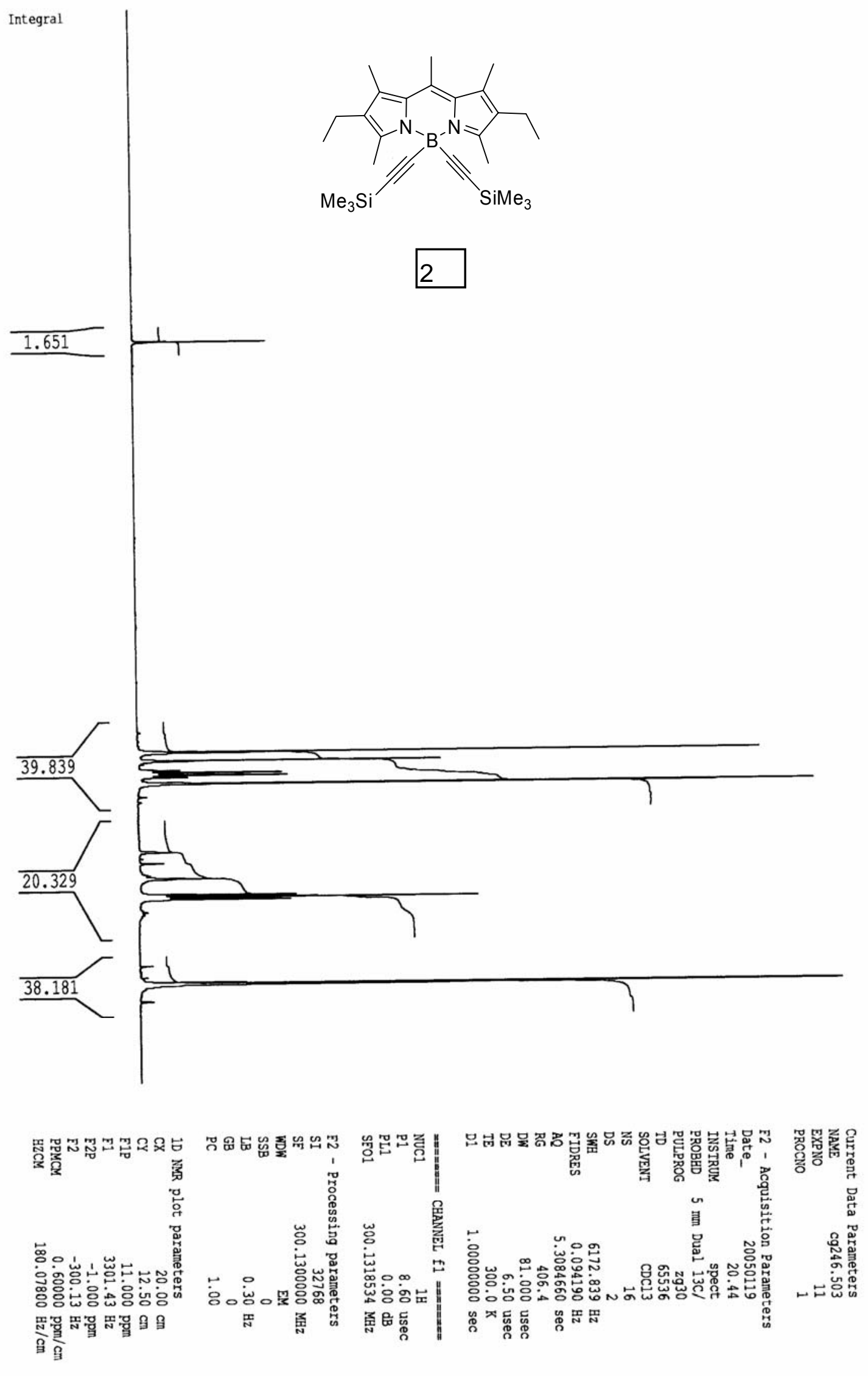


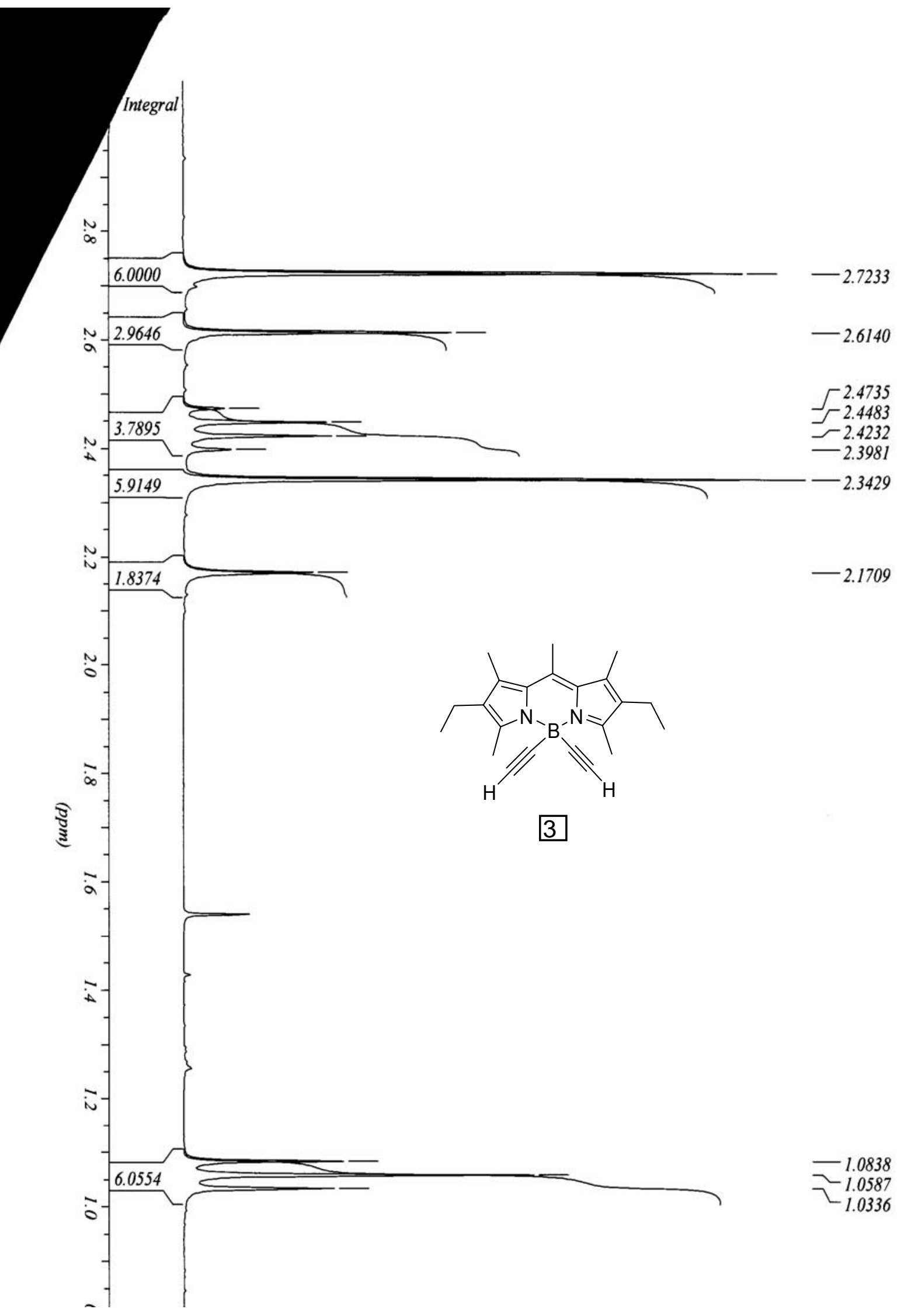




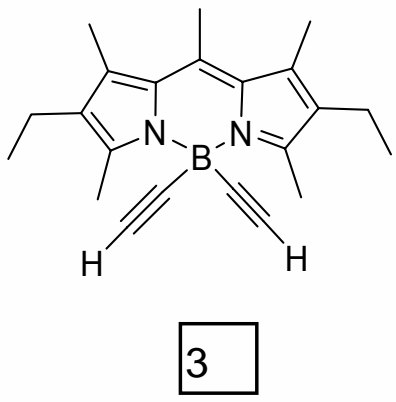

$-151.9265$

$-139.7951$

$-134.7840$

$-132.7549$

$-130.1366$ 


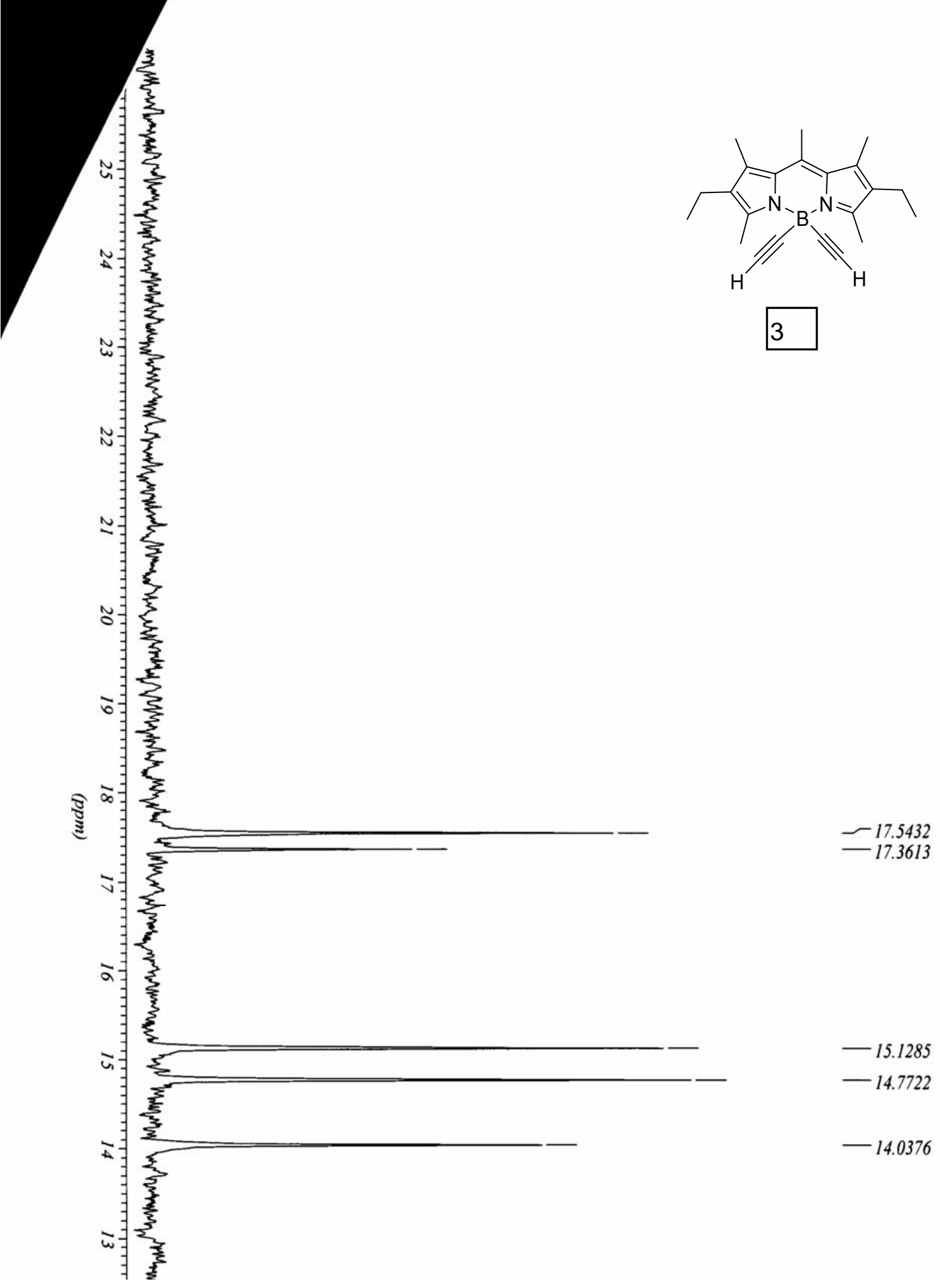





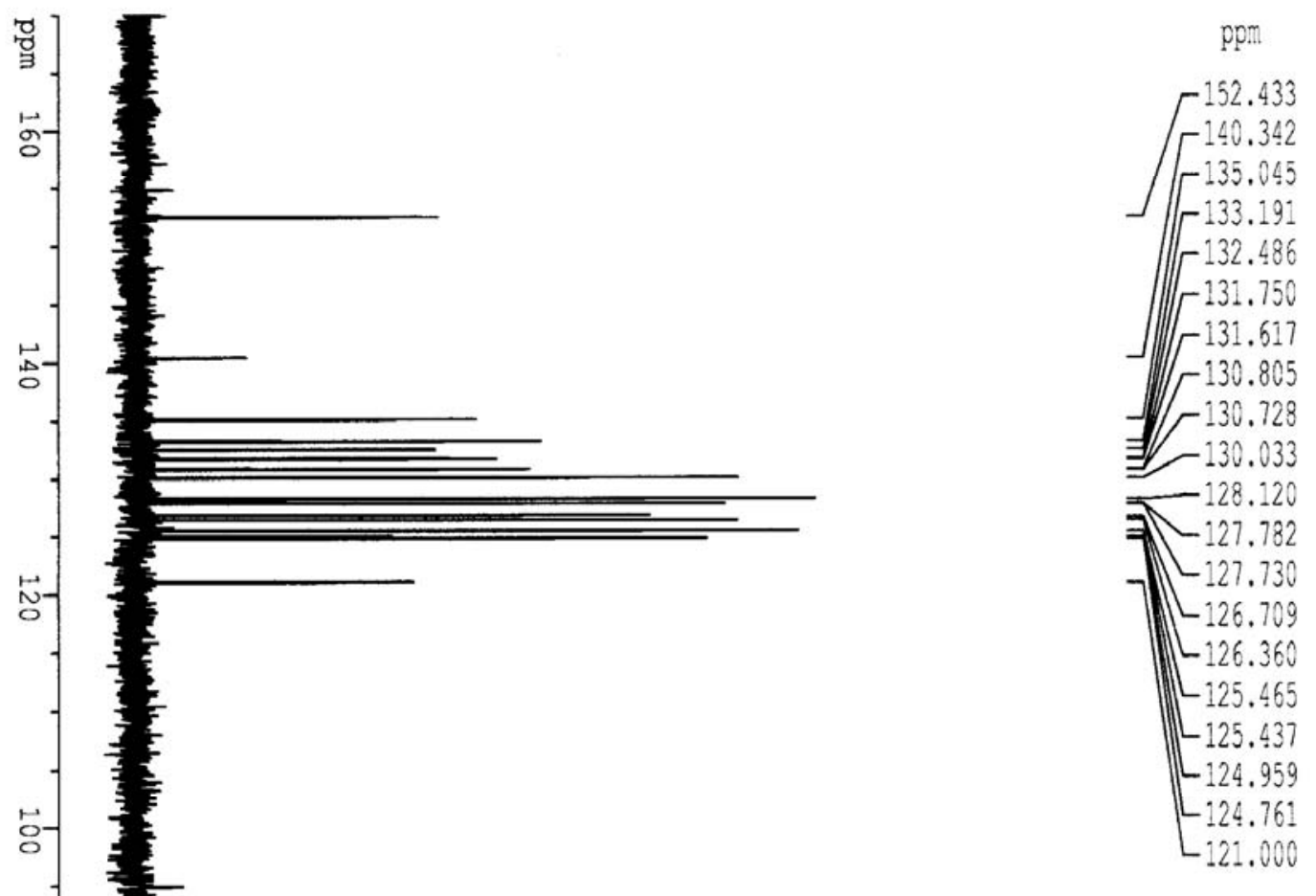



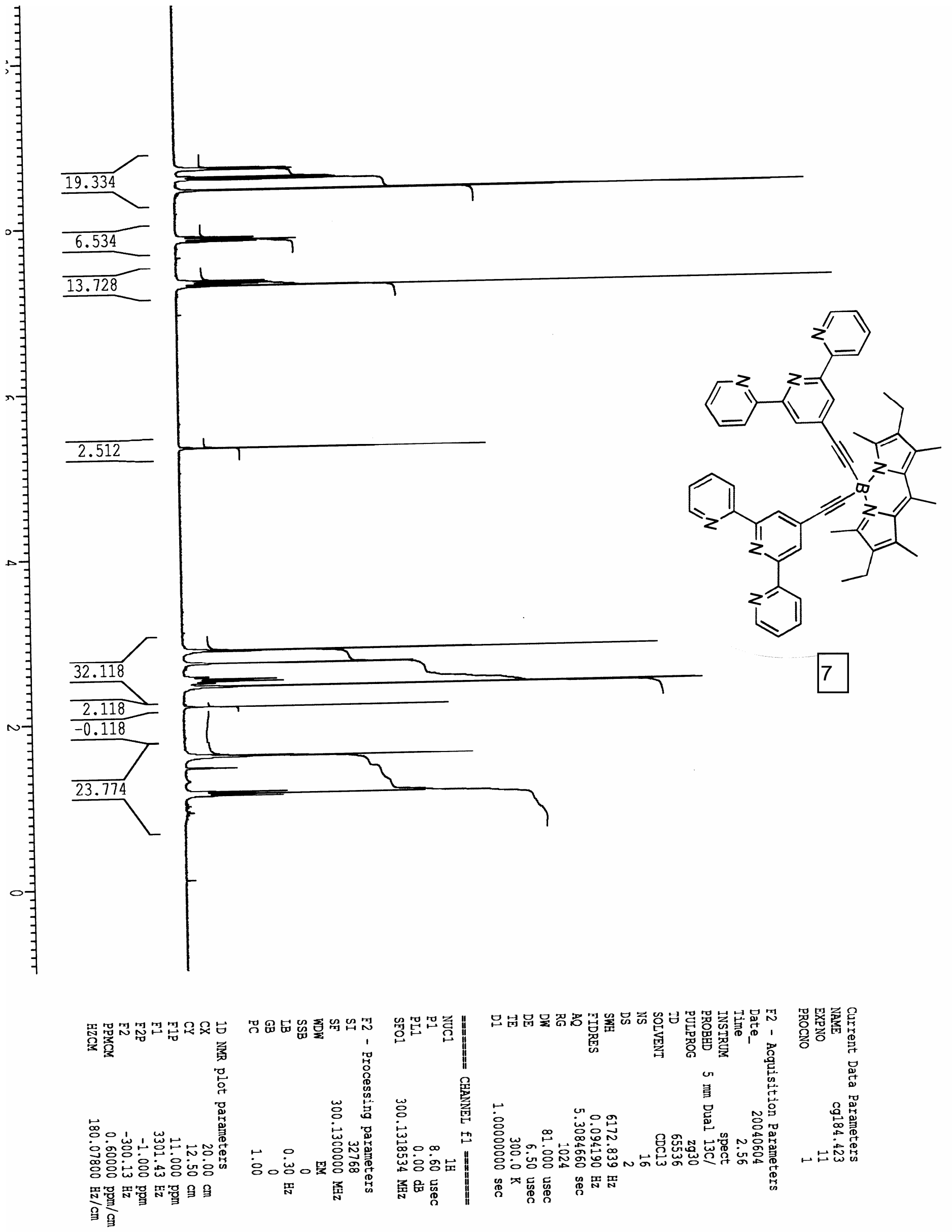

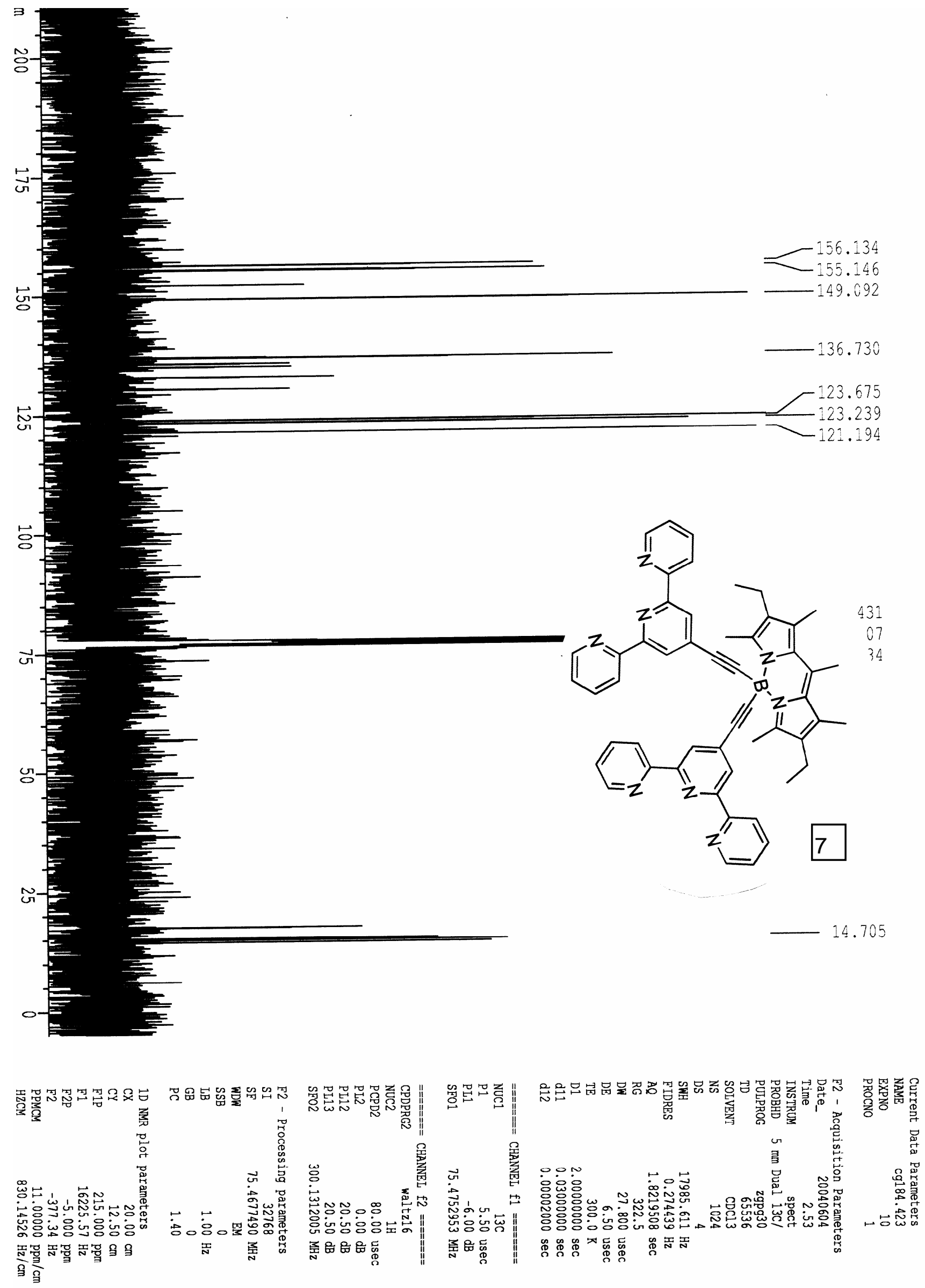


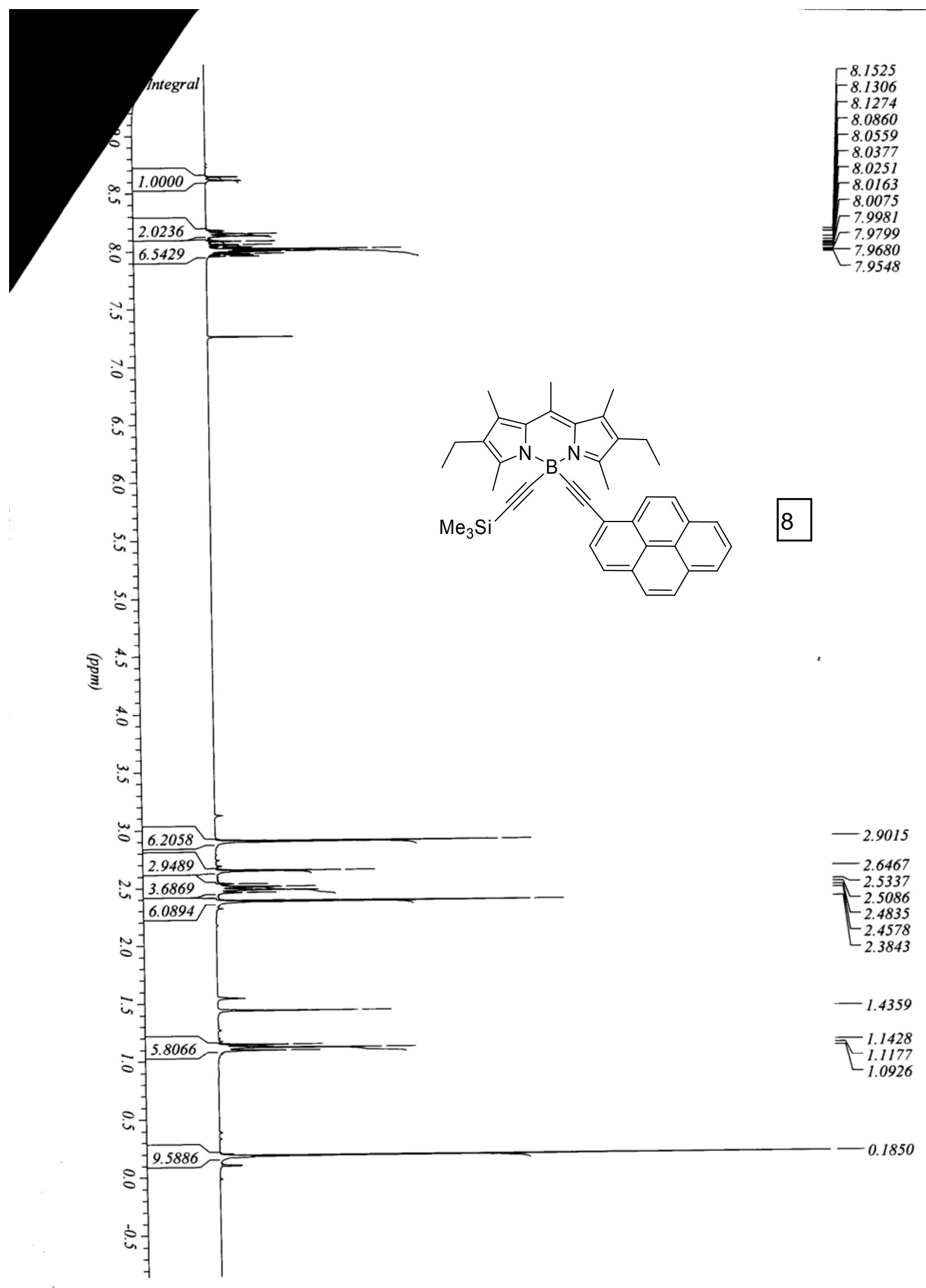




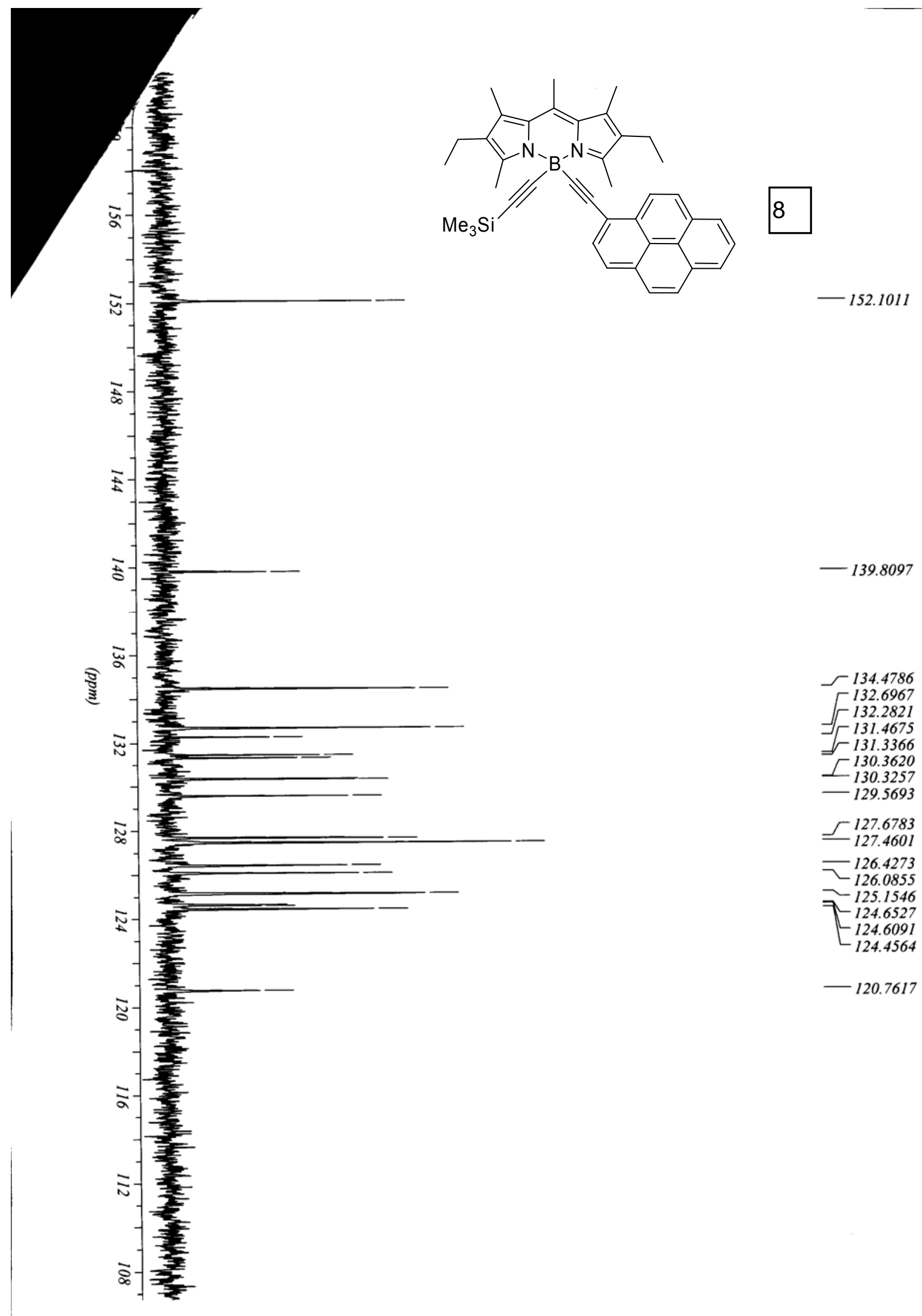




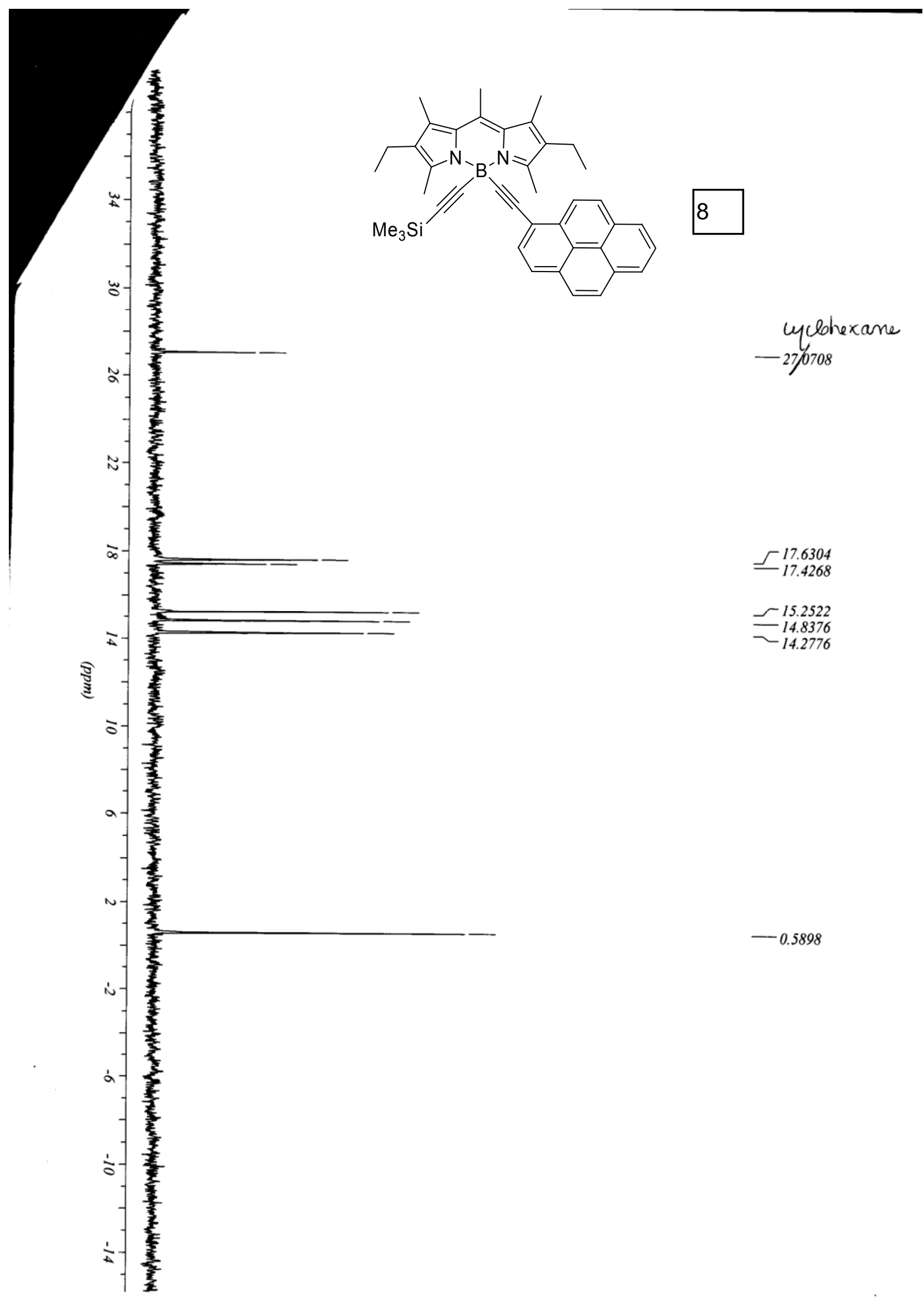




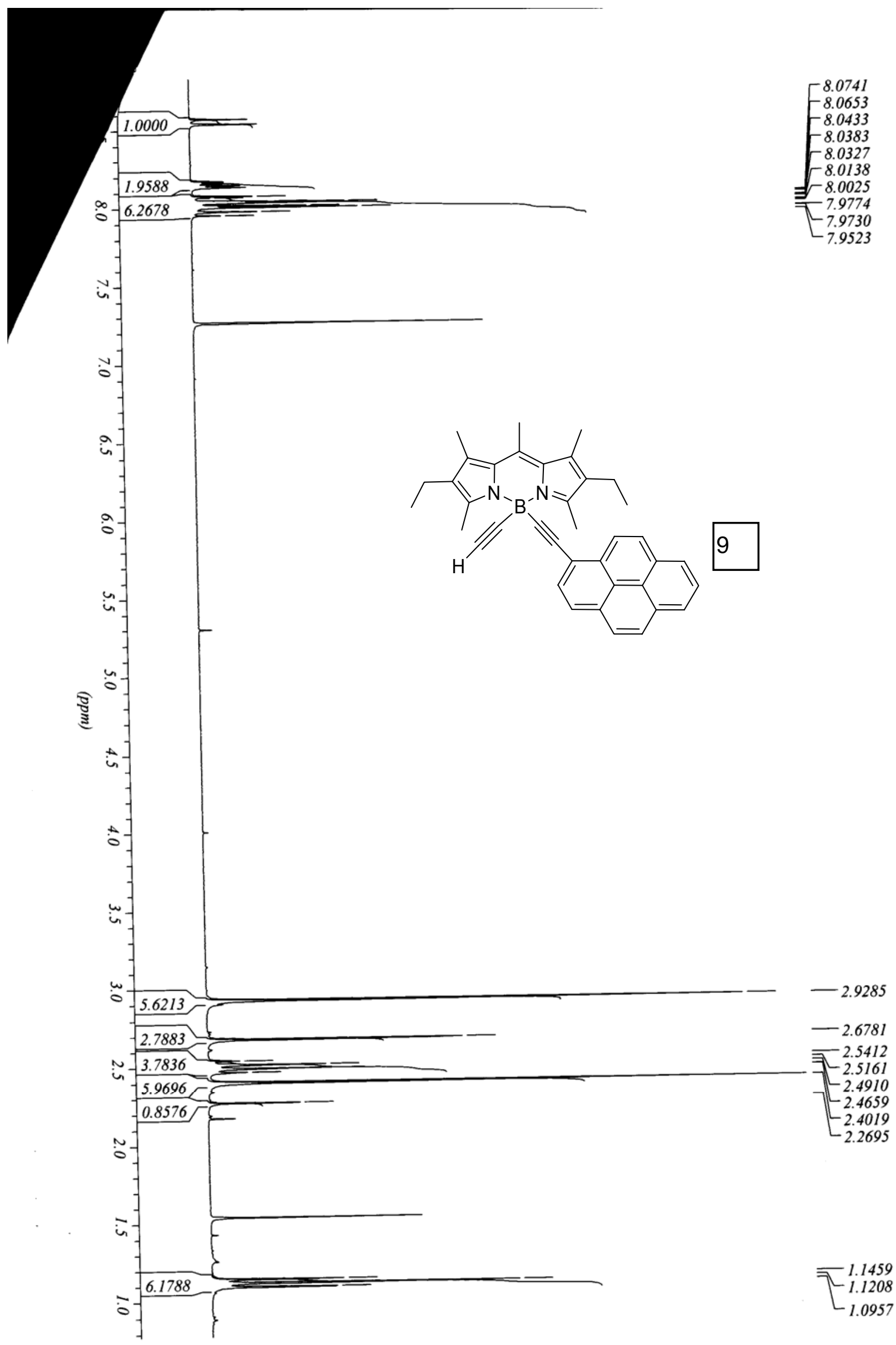



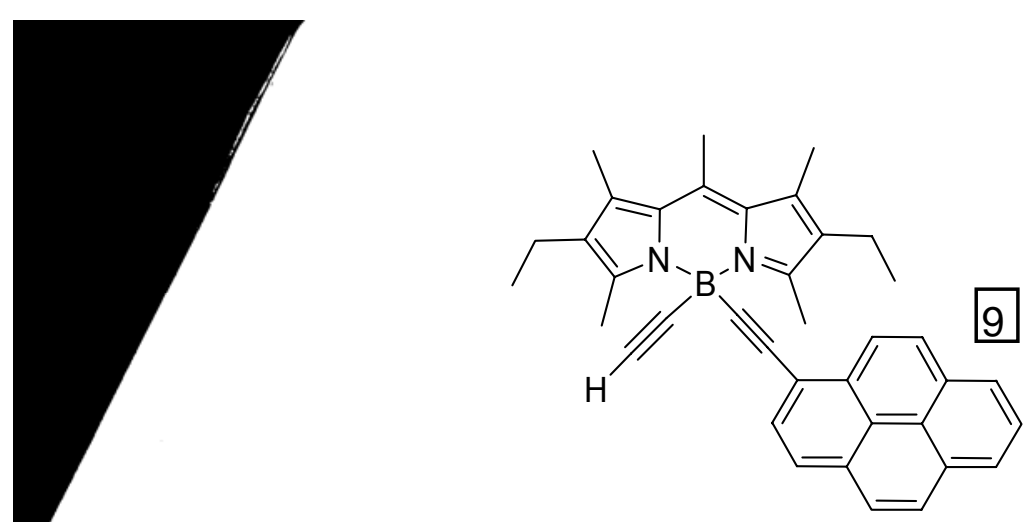

SEt $S^{\circ} O Z I-$

t9st

$I 609^{\circ}+2 I$

$6089+2 I \perp$

$286 I^{\circ} S Z I-$

I00I' $921-$

6198921

I09t' $\angle Z I-$

$\left.\begin{array}{l}8 Z E S ' \angle Z I] \\ Z 6 Z L \angle Z I\end{array}\right]$

$0208^{\circ} 621$

OEEE $0 \mathcal{E} I-\Gamma$

$\left.\varepsilon 6+t^{\circ} 0 \varepsilon I\right]$

$8+I \varepsilon \cdot I \varepsilon I-F$

EOSt IEI

OE60'ZEI

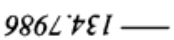

t296.68I -

IIZO'ZSI

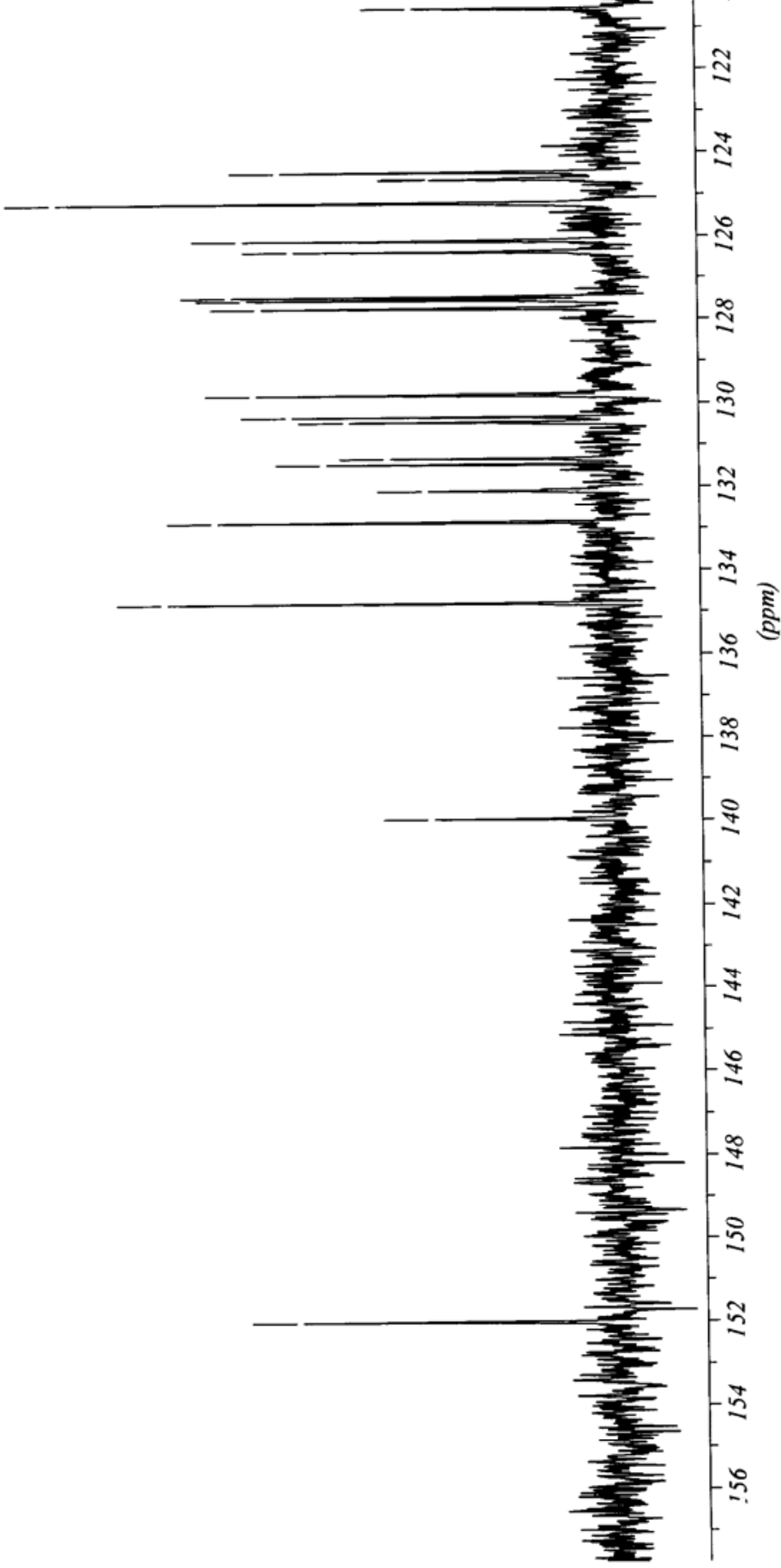




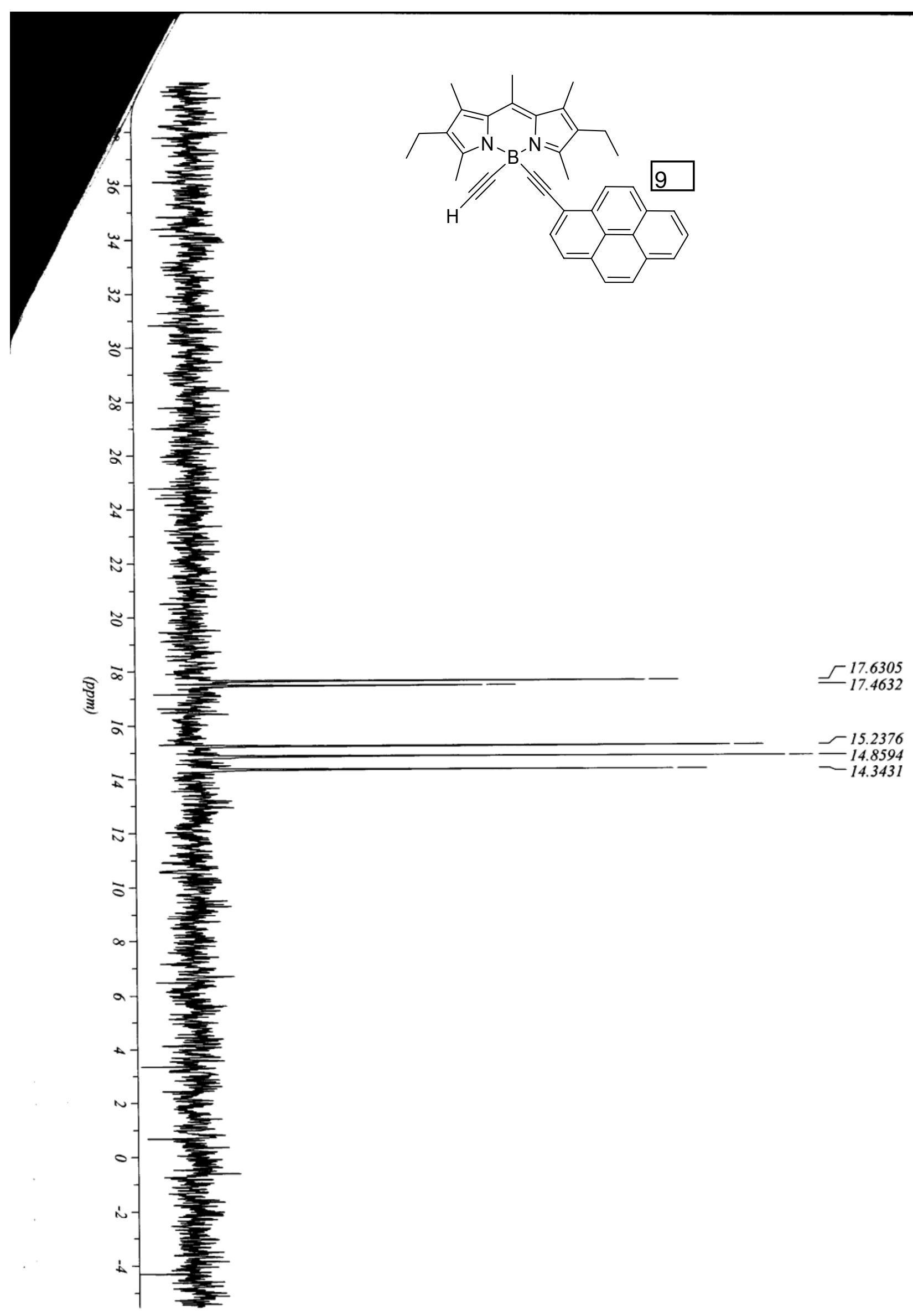




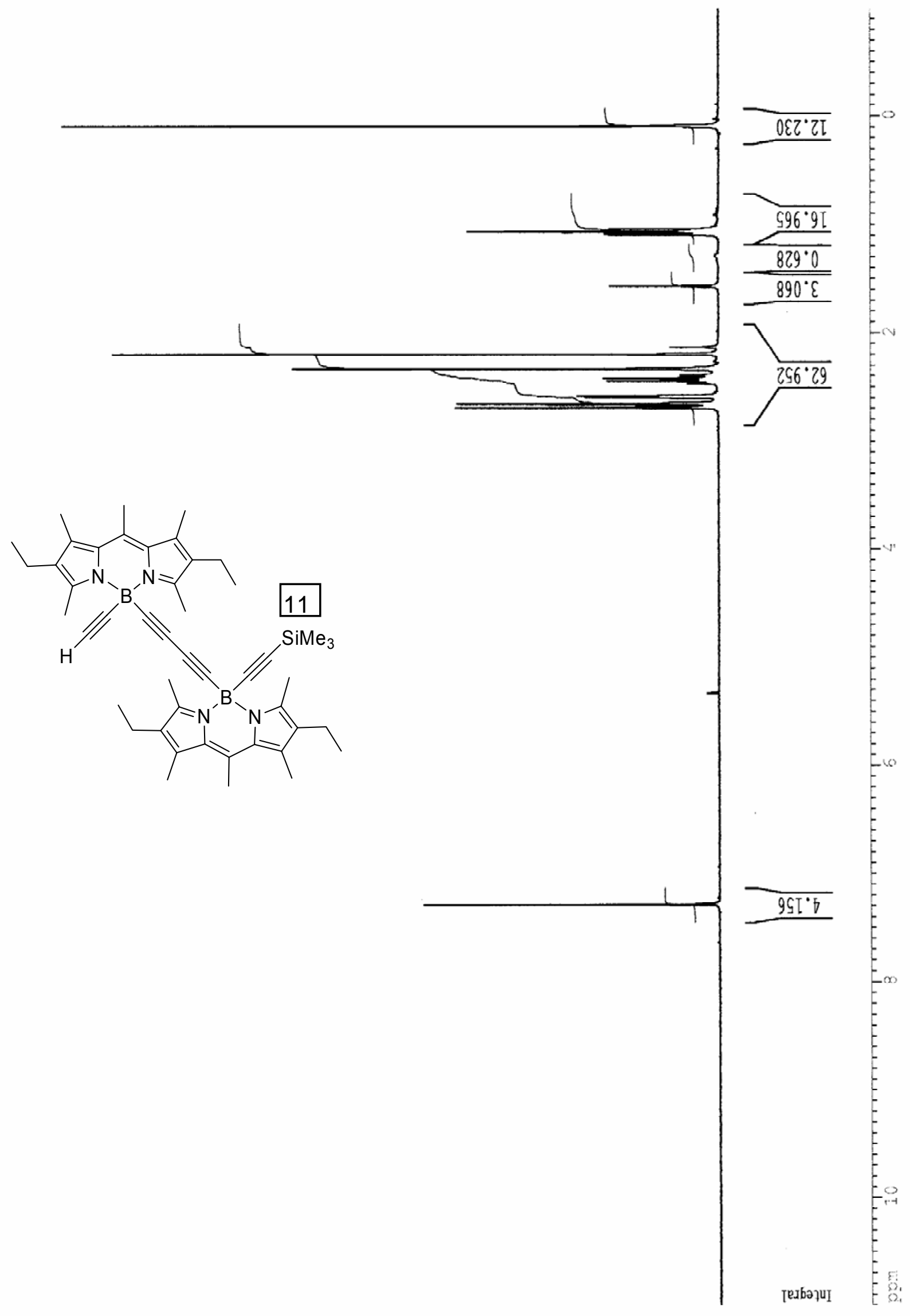




$$
k
$$




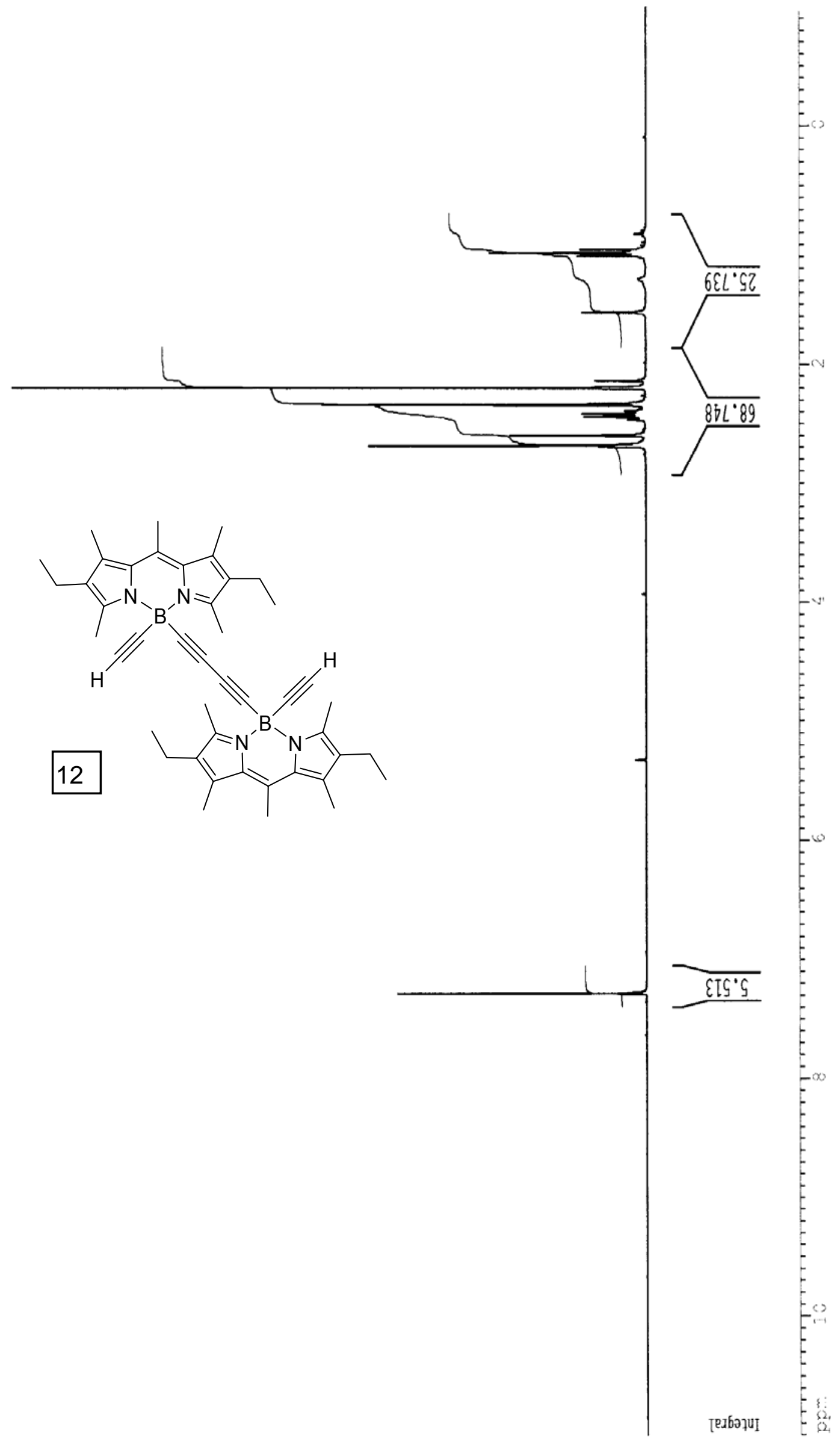




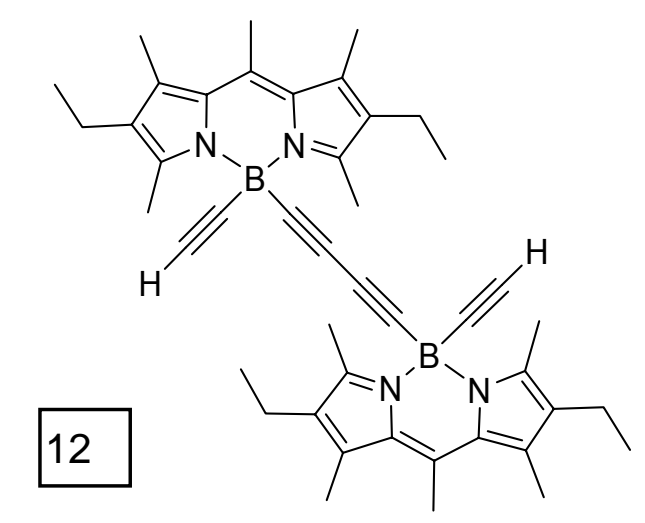

$\varepsilon 6+0.0 \varepsilon I-$

6ยZ9'ZEI

$6+6 \varsigma^{\circ}+\varepsilon I-$

$6 \angle t \varsigma^{\circ} 6 \varepsilon I-$

$6 Z+0 \cdot Z S I$
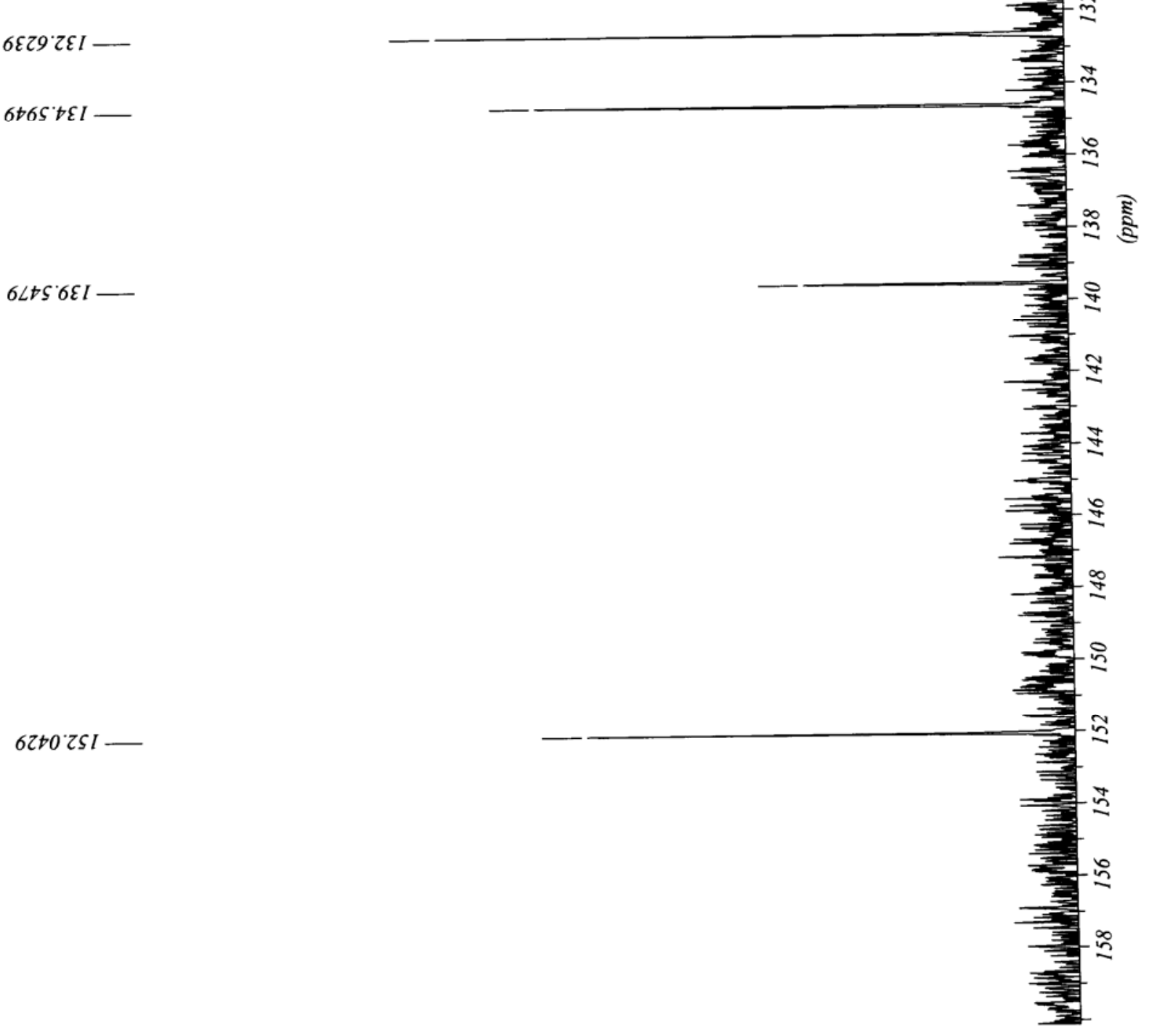
OEOI't I -

$I E D L ' D I-$
SBZI $S I--$

$6562: \angle I-$
$+I Z S \angle I-$

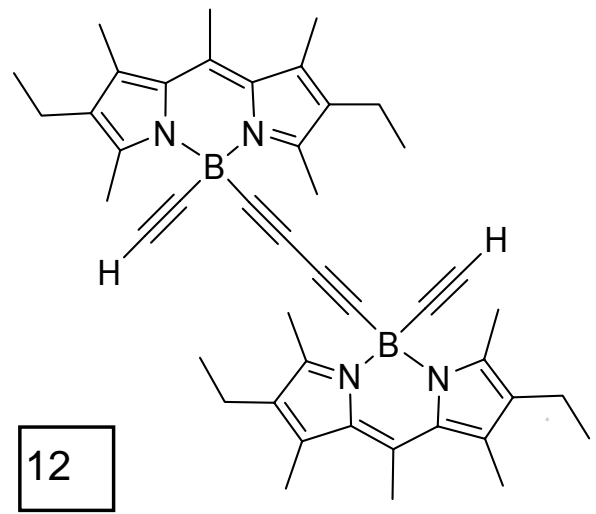

Z8LO IE

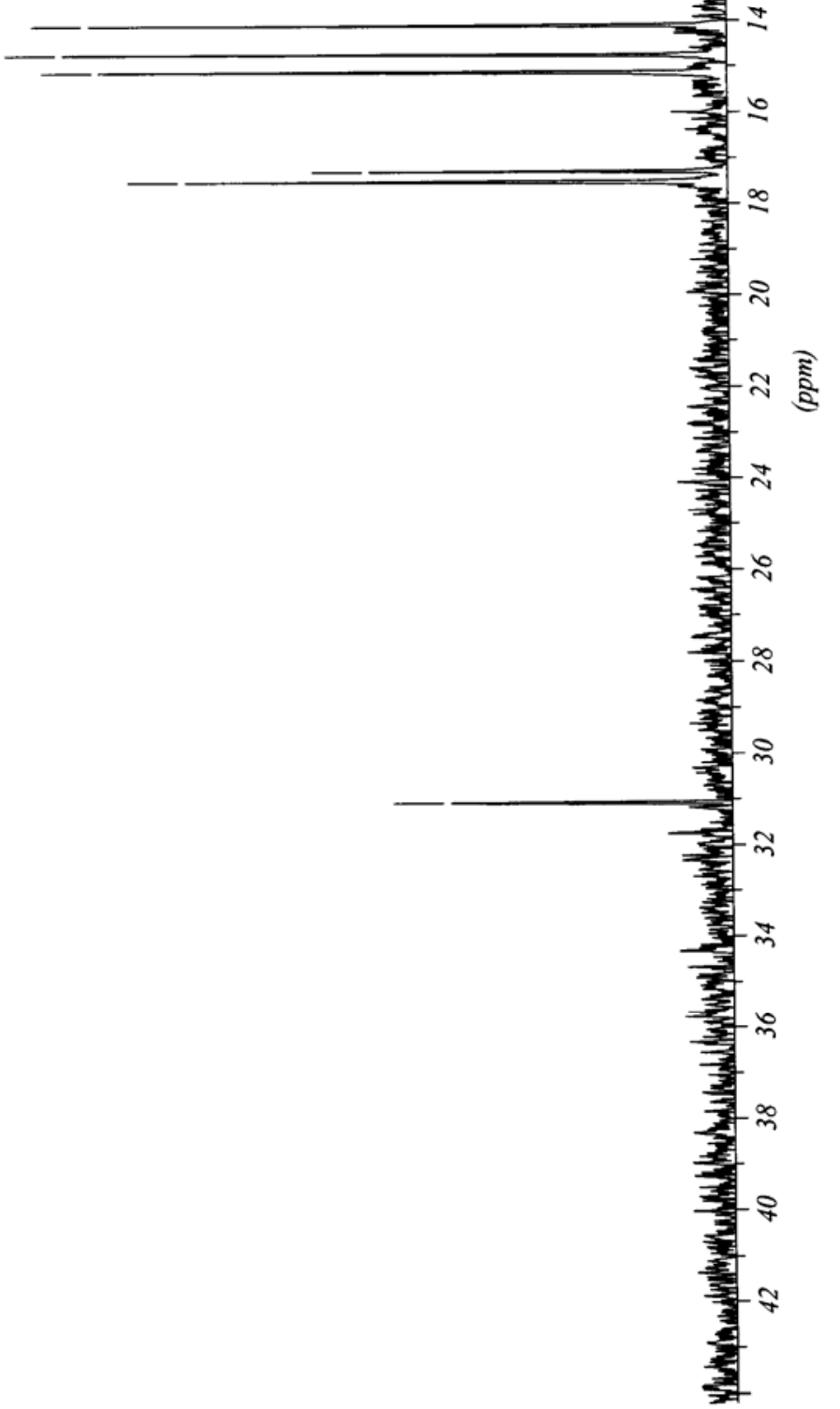

